\title{
ANÁLISE DE SUSTENTABILIDADE DA ÁREA RURAL DO MUNICÍPIO DE TRIUNFO (PE)
}

\author{
Bárbara Denise Ferreira Gonçalves* \\ Tales Wanderley Vital ${ }^{* *}$
}

RESUMO: Este trabalho investiga o desenvolvimento rural sustentável de Triunfo (PE), com o objetivo de verificar se esse tipo de desenvolvimento vem ocorrendo no município e com que intensidade. Para isso, foi tomado como referência o modelo de Sachs, que considera a sustentabilidade no meio rural a partir das dimensões social, ecológica e econômica. A esse modelo teórico de desenvolvimento sustentável foram incorporados indicadores de sustentabilidade do IBGE, resultando na elaboração de um modelo analítico, que foi aplicado utilizando dados obtidos nos levantamentos realizados. Como resultado, observou-se para o meio rural de Triunfo (PE) grande dependência das políticas públicas, principalmente aquelas dirigidas à agricultura familiar, como principal apoio aos residentes da área rural. Foi identificado que a sustentabilidade desse meio rural está em andamento devido ao fato de que a maioria dos pequenos produtores, em razão das secas ocorridas, não tem conseguido manter ou ampliar as atividades produtivas de suas unidades de produção, nem incorporar práticas ecologicamente corretas. Contudo, socialmente essa área rural, devido à ação de entidades religiosas, sindicais e da sociedade civil, tem um perfil diferenciado de empoderamento das comunidades rurais. Conclui-se que as ações de sustentabilidade econômica, ambiental e social estão em processo de construção no município, e são assimétricas e de baixa intensidade.

PALAVRAS-CHAVE: Atores sociais; Desenvolvimento rural sustentável; Sustentabilidade local.

\section{ANALYSIS OF SUSTAINABILITY OF THE RURAL AREA IN TRIUNFO, BRAZIL}

ABSTRACT: The sustainable rural development of Triunfo PE Brazil is analyzed so that the type of development in the municipality and its intensity could be investi-

\footnotetext{
"Mestre em Administração e Desenvolvimento Rural. Universidade Federal Rural de Pernambuco (UFRPE), Brasil. E-mail: barbara triunfo@hotmail.com

** Engenheiro Agrônomo. Pós-doutor em Economia Territorial por Grenoble II. Docente Associado III da Universidade Federal Rural de Pernambuco. Brasil.
} 
gated. Sachs's model, which considers sustainability in the rural area under the social, ecological and economy dimensions, is taken as a reference. IBGE sustainability indicators were incorporated to this theoretical model of sustainable development. An analytic model was consequently prepared and applied through data from surveys. Results show that the rural milieu of Triunfo, Brazil, largely depends on public policies, especially those foregrounded on familiar agriculture, as the main support of its rural inhabitants. The sustainability of the rural milieu is still in progress due to the fact that most small producers failed to maintain or widen their production in their units because of successive droughts, nether could they incorporate ecologically correct practices. On the other hand, due to the activities of religious agents, trade union and civil society, the rural area is characterized by the empowerment of rural communities. Activities implying economic, environmental and social sustainability are in the process of constructing the municipality, albeit asymmetrical and low density.

KEY WORDS: social agents; sustainable rural development; local sustainability.

\section{INTRODUÇÃO}

Desenvolvimento é um conceito dinâmico que atinge distintamente as áreas envolvidas e as populações afetadas. Algumas dessas, por sua vez, podem não se beneficiarem tão amplamente quanto outras durante o percurso. O desenvolvimento, na particularidade do rural, pode parecer uma questão simples e bem estabelecida na teoria, mas, de fato, tem sido motivo de controvérsias, entre as mais discutidas está a possibilidade de conciliar desenvolvimento e sustentabilidade (SAMPAIO; VITAL, 2015).

No semiárido com períodos prolongados de escassez hídrica, devido à aridez do clima, a imprevisibilidade das precipitações pluviométricas e a presença de solos pobres em matéria orgânica são desafios que, para serem enfrentados nessa região, exigem a persistência de estratégias sustentáveis de desenvolvimento (SILVA, 2008).

O semiárido brasileiro apresenta como principais problemas a escassez e a degradação dos recursos hídricos, potencializados pela gradual e permanente destruição dos recursos naturais, ao lado da insistência de implantação progressiva de 
atividades incompatíveis com esse meio ambiente (BARROS JUNIOR et al., 2015, p. 2).

Nesse cenário, muitas ações públicas vêm sendo testadas para a melhoria da qualidade de vida no campo. Nos anos setenta do século passado teve-se o Programa de Desenvolvimento de Áreas Integradas do Nordeste - POLONORDESTE (GOMES, 1996). Ainda, de acordo com Nabuco (2007), na região muitas áreas apresentam distintos índices de aridez, mas em algumas delas destacam-se particularidades geográficas com características como o balanço hídrico positivo e presença de solos bem desenvolvidos viabilizando o aproveitamento das potencialidades agropecuárias.

Nesse contexto, foram selecionadas áreas para execução do POLONORDESTE e, em alguns casos, sua atuação ocorreu em áreas de Serras Úmidas correspondendo às Serras da Ibiapaba e Baturité, no Estado do Ceará, Araripe, nos Estados do Ceará e Pernambuco, Martins, no Estado do Rio Grande do Norte, do Teixeira e do Brejo, no Estado da Paraíba, e de Triunfo, no Estado de Pernambuco (BRASIL, 1974).

Triunfo (PE) está localizado em uma área de serra de altitude elevada com microclima, que contrasta com a paisagem dominante do semiárido e constitui uma reserva com possibilidade de desenvolvimento diferenciado e sustentável. Considerando a importância desse debate na atualidade, esse trabalho busca verificar o desenvolvimento sustentável, em suas esferas social, ecológica e econômica, nas áreas rurais do município de Triunfo $(\mathrm{PE})$, com o objetivo de identificar se este realmente existe e como vem ocorrendo.

Portanto, a escolha do local de realização dessa pesquisa justifica-se quando se considera o conjunto de fatores que norteiam a trajetória das ações de sustentabilidade realizadas nesse município e apresentadas adiante:

Microclima do Sertão: Por estar a uma altitude de $1.260 \mathrm{~m}$, Triunfo (PE) apresenta um clima tropical/brejo de altitude que contradiz com a aridez do sertão nordestino, de modo que, apesar das características da realidade regional, é menos propício às calamidades da seca do semiárido.

Influência da cultura religiosa: Triunfo (PE) tem na religiosidade sua marca como destaque. No município, a cultura sertaneja recebeu influência da Europa, tendo sua história fortemente ligada à religião católica: padres, capuchinos, freis e freiras, de diversas localidades e países, participaram da construção do município e de sua identidade 
Polo turístico: o clima ameno de Triunfo (PE) proporciona temperaturas baixas que na época mais fria chega a cerca de $10^{\circ} \mathrm{C}$. Essa temperatura, entre outras particularidades como os pontos turísticos naturais, agregam valores intangíveis ao município.

O município está localizado na mesorregião Sertão Pernambucano, microrregião Pajeú, com uma área territorial de $181,4 \mathrm{~km}^{2}$. De acordo com o IBGE (2010) possui uma população estimada em 15.006 habitantes e é caracterizado pela presença de comunidades rurais que em termos de pessoas que residem no campo somam 7.062 habitantes, o que representa significativamente a população do meio rural. Os estabelecimentos rurais somam 2.058 sendo 1.938 de agricultura familiar. Ocupam áreas de 14.528 ha e 9.956 ha respectivamente (IBGE, 2006).

Ainda, a forma como geograficamente as comunidades rurais de Triunfo apresentam-se permite concluir que existe um conjunto de três realidades distintas: uma área alta, uma área mediana, e uma área ao pé da Serra da Baixa Verde.

As comunidades rurais que estão localizadas na proximidade do ponto mais alto do município, o Pico do Papagaio, apresentam particularidades como melhores condições ecológicas, maior preservação ambiental, grandes áreas de cultivos, solo mais fértil e, por conseguinte, melhores condições para implantação de quintais produtivos, cultivo de produtos variados, e viveiro de mudas de plantas.

$\mathrm{Na}$ área que possui uma altitude mediana, o meio ambiente é preservado em sua maior parte, porém é constatado que houve uma maior incidência de desmatamentos e de queimadas ao longo do tempo. Desse modo, algumas propriedades das famílias agricultoras já não têm a capacidade natural de produção agrícola, de forma que muitas famílias dependem da assessoria técnica rural para orientação de práticas para a recuperação do solo.

Já a área localizada ao pé da Serra da Baixa Verde tem condições completamente diferentes como a presença de solos mais áridos que têm maior dificuldade quanto à recuperação quando se deparam com a desertificação e com a perda de sedimentos e matéria orgânica. Tecnologias de convivência com o semiárido implantadas nessa área, como sistemas agroflorestais, têm um processo de desenvolvimento mais longo uma vez que a condição climática é diferenciada.

Diante desse quadro enfatiza-se que as comunidades rurais localizadas na parte mais alta do município têm áreas de produção agrícola mais extensas com o 
café, a banana e a cana-de-açúcar, principais culturas agrícolas da localidade.

\section{MATERIAL E MÉTODOS}

\subsection{O MODELO ANALIITICO DE DESENVOLVIMENTO SUSTENTÁVEL}

\subsubsection{Aspectos conceituais}

Segundo o Relatório da Comissão Mundial sobre o Meio Ambiente e o Desenvolvimento - CNUMAD, da Organização das Nações Unidas - ONU, publicado em 1987, o desenvolvimento sustentável é aquele que satisfaz as necessidades presentes, sem comprometer a capacidade das gerações futuras de suprir suas próprias necessidades (BURSZTYN; BURSZTYN, 2006). Como visto, a noção de desenvolvimento sustentável é introduzida no cenário internacional a partir do debate sobre a sustentabilidade ambiental realizado por essa Comissão acerca dos riscos do uso excessivo dos recursos naturais sem considerar a capacidade de suporte dos ecossistemas.

Por outro lado, a Agenda 21 Global foi um dos principais resultados da Conferência das Nações Unidas sobre Meio Ambiente e Desenvolvimento, em 1992, no Rio de Janeiro - Brasil, conhecida como Rio 92. Trata-se de um documento político que constitui a mais abrangente tentativa já realizada de promover, em escala planetária, um novo padrão de desenvolvimento, denominado "desenvolvimento sustentável". E, o termo "Agenda 21", foi usado no sentido de intenções, desejo de mudança para esse novo modelo de desenvolvimento para o século XXI (BRASIL, 2012).

A Agenda 21 do Brasil foi o resultado de uma vasta consulta à população brasileira tendo sido montada a partir das ações estratégicas da Agenda 21 Global (MMA, 2012). As áreas dessa agenda que mais receberam atenção foi a de gestão de recursos naturais e de agricultura sustentável em função de ser a conservação dos espaços naturais e rurais desafios associados à sustentabilidade (BORN, 2002).

Dentro desse contexto, o Instituto Brasileiro de Geografia e Estatística IBGE publicou em 2002 os Indicadores de Desenvolvimento Sustentável - Brasil, por meio dos quais é possível se proceder a avaliação de políticas públicas do país nas 
diferentes dimensões do desenvolvimento (MALHEIROS; PHLIPPI JÚNIOR; COUTINHO, 2008). A questão colocada é precisamente a escolha do desenvolvimento que busca a prudência ecológica, a justiça social e a eficiência econômica, desde que o modelo convencional frente à crise ambiental revelou a necessidade de alteração desse modelo para um outro sustentável (LAYRARGUES, 1997).

Segundo Sachs (2002), os pilares do desenvolvimento sustentável devem atender simultaneamente aos critérios de sustentabilidade social, prudência ecológica e viabilidade econômica, sobre os quais deve-se implementar uma estratégia de desenvolvimento comprometida com essas bases.

Ao investigar o desenvolvimento sustentável deve-se considerar se o conjunto dos diversos atores, entre estes a sociedade civil organizada e as instituições, estão envolvidas por um objetivo que direciona seus comportamentos e suas estratégias para a sustentabilidade (SIMÃO et al., 2010, p. 35).

O modelo teórico de desenvolvimento sustentável exige a formulação de políticas públicas nas dimensões espacial, cultural, ambiental ou ecológica, econômica e social (SILVA; SOUZA-LIMA, 2010, p. 13). Assim, a sustentabilidade é compreendida a partir de suas múltiplas dimensões, em que a dimensão social defende o acesso a direitos, à terra, à proteção do Estado e ao exercício pleno de opções e escolhas relativas à cultura e tradições. A dimensão ecológica pressupõe o manejo e o uso sustentável dos recursos naturais, eliminando práticas danosas ao meio ambiente. $\mathrm{E}$ a dimensão econômica implica a viabilização de atividades produtivas aliadas à distribuição equitativa da renda gerada (CONDRAF, 2010a). A sustentabilidade descrita por Ferreira (2011) remete à relação do ser humano com a natureza, a qual exige integrar os componentes socioeconômicos e ambientais, como também a atuação de agentes sociais mais dinâmicos e articulados em âmbito local.

Em torno de todo esse contexto, as políticas públicas na agricultura procuram definir os atores sociais envolvidos, suas iniciativas, projetos, processos, discursos e práticas e, por conseguinte, compreender esses elementos que, embora estando em diferentes âmbitos e esferas da arena pública, agem de forma articulada e guiados por estratégias de luta e de mobilização que pode também buscar o desenvolvimento rural sustentável (VARELLI et al., 2011, p. 45).

Segundo o Condraf (2010b), a Política de Desenvolvimento do Brasil Rural adotou uma concepção que qualifica o rural a partir de três características funda- 
mentais que coexistem e se complementam: i) área de produção agropecuária, agroindustrial, comercial, de prestação de serviços e de atividades de lazer; ii) espaço de vida de organização social e de produção cultural para as pessoas que nele residem; iii) ser um espaço privilegiado de relação com a natureza.

Com isso, um aspecto importante consiste na aplicação de práticas de política pública de sustentabilidade no meio rural que, a depender da sua natureza, realiza ações considerando cada uma das características desse novo mundo rural.

\subsubsection{Especificação do modelo}

Para esse trabalho o modelo analítico foi construído a partir da concepção do atual mundo rural estabelecido segundo a política de desenvolvimento do Brasil rural (CONDRAF, 2010b), do modelo de Sachs (2002), sobre a sustentabilidade que é vista no plano social, ambiental e econômica dentro de uma estabilidade política e, ainda, com a incorporação de indicadores propostos e publicados pelo IBGE (2002), com as devidas adaptações para o meio rural do município de Triunfo (PE). Esse modelo analítico compreende três dimensões para o desenvolvimento rural sustentável: i) a Social; ii) a Ecológica; iii) e a Econômica, cujos componentes de análise são apresentados na Figura 1 a seguir.

Ao se pensar em indicadores de sustentabilidade, torna-se essencial que eles partam de informações existentes.

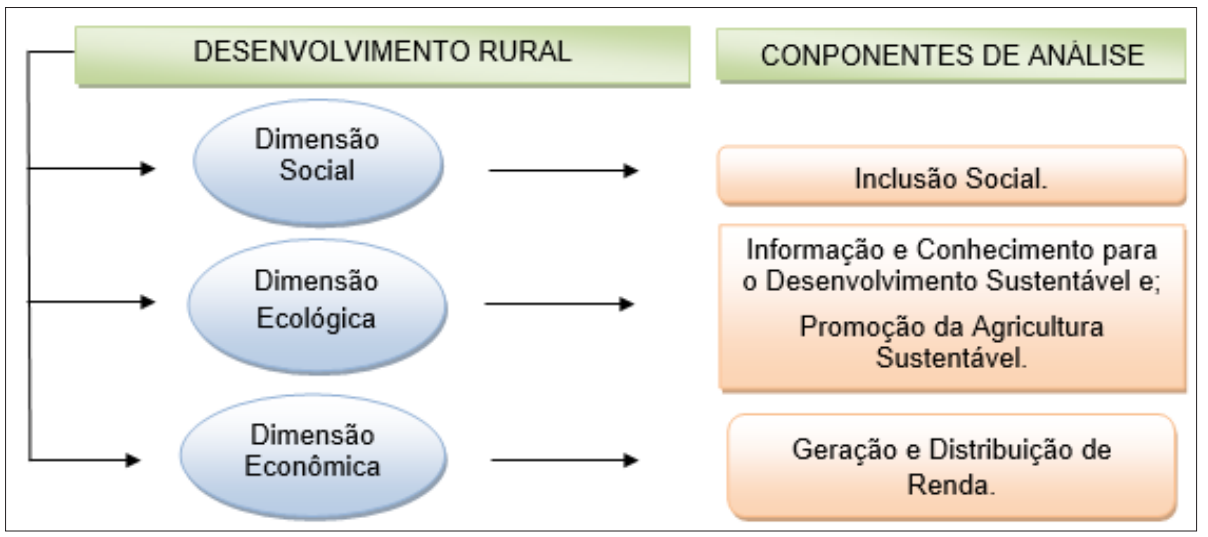

Figura 1. Modelo Analítico de Sustentabilidade Fontes: Sachs (2002); Silva e Souza-Lima (2010); e IBGE (2002). (Indicadores Adaptados, 2017). 


\subsubsection{Dimensão social}

Entende-se pela dimensão social a capacidade de organização e articulação das comunidades rurais através das associações, para resolver problemas e demandas de residentes na área rural de Triunfo (PE).

Assim, a análise da dimensão social que trata da inclusão social foi realizada através das seguintes variáveis e indicadores:

VS1 - Associações de comunidades rurais, membros participantes e funcionamento no município.

$\mathrm{IS}_{1}=$ número de associações rurais/número de comunidades rurais.

$\mathrm{IS}_{2}=$ número de associados representando famílias rurais das associações/ número de famílias rurais do município.

$\mathrm{IS}_{3}=$ número de associados das associações rurais/número de associações rurais.

VS2 - Participação das associações rurais em ações sociais e nos Projetos de Programas Sociais do município.

$\mathrm{IS}_{4}=$ número de associações rurais com projetos de tecnologias sociais/ número de associações rurais.

\subsubsection{Dimensão ecológica}

Entende-se pela dimensão ecológica a existência de práticas de proteção ambiental que têm por finalidade proteger o que está em condições ecologicamente equilibradas e recuperar o que foi degradado. O componente ecológico foi verificado através das seguintes variáveis e indicadores:

VE1 - Principais problemáticas ambientais existentes.

VE2 - Projetos de proteção ambiental e de agricultura sustentável existentes. 
$\mathrm{IE}_{1}=$ número de projetos de proteção ambiental nas associações/número de associações rurais.

$\mathrm{IE}_{2}=$ número de projetos de agricultura sustentável nas associações/número de associações rurais.

VE3 - Associações que atuam com ações e projetos ambientais e de agricultura sustentável.

$\mathrm{IE}_{3}=$ número de associações que realizam ações e projetos ambientais e de agricultura sustentável/número de associações rurais.

\subsubsection{Dimensão econômica}

A dimensão econômica será vista a partir do componente Geração e Distribuição de Renda através dos seguintes variáveis e indicadores:

VEc1 - Evolução do Produto Interno Bruto do Setor Agropecuário no município.

$V E c 2$ - Evolução das atividades da agropecuária no município.

VEc3 - Programas e Projetos de apoio à atividade agropecuária sustentável.

$\mathrm{IEc}_{1}=$ número de beneficiários das associações rurais participantes do PRO$\mathrm{NAF} /$ número de agricultores de estabelecimentos da agricultura familiar.

$\mathrm{IEc}_{2}=$ número de beneficiários das comunidades rurais participantes do $\mathrm{PAA} /$ número de agricultores de estabelecimentos da agricultura familiar.

$\mathrm{IEc}_{3}=$ número de beneficiários das comunidades rurais participantes do PNAE/número de agricultores de estabelecimentos da agricultura familiar.

$\mathrm{IEc}_{4}=$ número de beneficiários das associações rurais participantes do Programa Terra Pronta/número de agricultores vinculados às associações rurais. $\mathrm{IEc}_{5}=$ número de beneficiários das associações rurais participantes do Programa Distribuição de Sementes/número de agricultores vinculados às associações rurais. 


\subsection{FONTE DE DADOS}

Em Triunfo (PE), município localizado no Sertão do Pajeú, a área rural tem ainda forte influência na vida dos seus habitantes. Está representada por um total de 36 comunidades rurais, sendo que 33 dessas comunidades têm associações. Foram obtidas informações em 25 associações, correspondendo a $76 \%$ do total, mediante entrevistas dirigidas. Além disso, foram mapeadas as principais instituições do município que atuam nas comunidades rurais (Quadro 1) e verificada a natureza da gestão de cada uma delas.

Quadro 1. Instituições de apoio à gestão da agricultura em Triunfo (PE).

\begin{tabular}{|l|l|}
\hline INSTITUIÇÃo & \multicolumn{1}{|c|}{ NATUREZA } \\
\hline $\begin{array}{l}\text { Sindicato dos Trabalhadores Rurais de Triunfo (PE) } \\
\text { (STR). }\end{array}$ & $\begin{array}{l}\text { Entidade de Classe - organização de produ- } \\
\text { tores rurais que representam seu trabalho. }\end{array}$ \\
\hline $\begin{array}{l}\text { Associação de Desenvolvimento Rural Sustentável } \\
\text { (ADESSU). }\end{array}$ & Organização Não-Governamental. \\
\hline $\begin{array}{l}\text { Centro de Desenvolvimento Agroecológico Sabiá } \\
\text { (Centro SABIÁ). }\end{array}$ & Organização Não-Governamental. \\
\hline $\begin{array}{l}\text { Conselho Municipal de Desenvolvimento Rural Sus- } \\
\text { tentável (COMDESTRI). }\end{array}$ & Organização Mista (Público-Privada). \\
\hline Instituto Agronômico de Pernambuco (IPA). & Instituição Pública Estadual. \\
\hline $\begin{array}{l}\text { Secretaria Municipal de Agricultura, Meio Ambiente } \\
\text { e Desenvolvimento Rural (SMAMDR). }\end{array}$ & Instituição Pública Municipal. \\
\hline $\begin{array}{l}\text { Cooperativa de Produção e Comercialização da } \\
\text { Agricultura Familiar Agroecológica (COOPCAFA). }\end{array}$ & Organização de Agricultores Familiares. \\
\hline
\end{tabular}

Fonte: Elaboração própria, 2016.

No levantamento de dados e informações acerca das variáveis e indicadores das dimensões social, ecológica e econômica para alimentar o modelo de análise, utilizou-se como instrumento de coleta de dados entrevista dirigida e aplicada aos dirigentes e lideranças das organizações vinculadas às referidas dimensões e também junto a representantes e/ou membros das associações de comunidades rurais mediante a aplicação de entrevista com questionário 
Já o levantamento realizado nas associações, com membros das comunidades, foi direcionado para verificar a compreensão desses participantes sobre o desenvolvimento sustentável, a identificação dos componentes desse desenvolvimento e os projetos e ações de sustentabilidade que são desenvolvidos na localidade. Foram obtidos também dados secundários advindos das bases de dados disponíveis nas instituições envolvidas (Quadro 2) e de documentos publicados e disponíveis em sites de agências oficias.

Quadro 2. Dados coletados para gerar os indicadores do modelo analítico

(continua)

\begin{tabular}{|c|c|c|c|}
\hline VARIÁVEIS DO MODELO POR COMPONENTE & UNIDADE & VALOR & FONTE (S) DA COLETA \\
\hline \multicolumn{4}{|l|}{ 1. Dimensão Social } \\
\hline Comunidades Rurais & Número & 36 & CONDESTRI e STR \\
\hline Associações de Comunidades Rurais & Número & 33 & CONDESTRI e STR \\
\hline Associados das Associações Rurais & Número & 1405 & CONDESTRI e Associações Rurais \\
\hline População Rural do Município & Número & 7.062 & IBGE - Censo 2010 \\
\hline Famílias Rurais do Município & Número & 1.844 & IBGE - Censo 2010 \\
\hline $\begin{array}{l}\text { Associações Rurais com Projetos de Tecnolo- } \\
\text { gias Sociais no Município }\end{array}$ & Número & 10 & $\begin{array}{l}\text { STR, ADESSU, Centro SABIÁ e le- } \\
\text { vantamento direto nas associações }\end{array}$ \\
\hline \multicolumn{4}{|l|}{ 2. Dimensão Ecológica } \\
\hline $\begin{array}{l}\text { Associações rurais com projetos de proteção } \\
\text { ambiental }\end{array}$ & Número & 5 & $\begin{array}{l}\text { STR, ADESSU, Centro SABIÁ e le- } \\
\text { vantamento direto nas associações }\end{array}$ \\
\hline $\begin{array}{l}\text { Associações rurais com projetos de agricultu- } \\
\text { ra sustentável }\end{array}$ & Número & 4 & $\begin{array}{l}\text { STR, ADESSU, Centro SABIÁ e le- } \\
\text { vantamento direto nas associações }\end{array}$ \\
\hline $\begin{array}{l}\text { Associações rurais com ações ambientais e de } \\
\text { agricultura sustentável }\end{array}$ & Número & 11 & $\begin{array}{l}\text { STR, ADESSU, Centro SABIÁ e le- } \\
\text { vantamento direto nas associações }\end{array}$ \\
\hline \multicolumn{4}{|l|}{ 3. Dimensão Econômica } \\
\hline Produto Interno Bruto do Município & $\mathrm{R} \$ 1000,00$ & 66198 & IBGE - Cidades - 2010 \\
\hline $\begin{array}{l}\text { Produto Interno Bruto do Setor Agropecuário } \\
\text { do Município }\end{array}$ & $\mathrm{R} \$ 1000,00$ & 5.771 & IBGE - Cidades - 2010 \\
\hline $\begin{array}{l}\text { Beneficiários das associações rurais partici- } \\
\text { pantes do PRONAF }\end{array}$ & Número & 1900 & IPA e SMAMDR \\
\hline $\begin{array}{l}\text { Beneficiários das comunidades rurais partici- } \\
\text { pantes do PAA }\end{array}$ & Número & 2035 & IPA e STR \\
\hline $\begin{array}{l}\text { Estabelecimentos da agricultura familiar do } \\
\text { Município }\end{array}$ & Número & 1938 & IBGE - Censo Agropecuário 2006 \\
\hline
\end{tabular}


(Conclusão)

\begin{tabular}{|l|c|c|c|}
\hline VARIÁVEIS DO MODELO POR COMPONENTE & UNIDADE & VALOR & FONTE (S) DA COLETA \\
\hline 3. Dimensão Econômica & & & \\
\hline $\begin{array}{l}\text { Agricultores nos estabelecimentos da agricul- } \\
\text { tura familiar do Município }\end{array}$ & Número & 7364 & IBGE - Censo Agropecuário 2006 \\
\hline $\begin{array}{l}\text { Beneficiários das comunidades rurais partici- } \\
\text { pantes do PNAE }\end{array}$ & Número & 1873 & COOPCAFA e STR \\
\hline $\begin{array}{l}\text { Beneficiários das associações rurais partici- } \\
\text { pantes do Programa Terra Pronta }\end{array}$ & Número & 1050 & IPA \\
\hline $\begin{array}{l}\text { Beneficiários das associações rurais parti- } \\
\text { cipantes do Programa de Distribuição de } \\
\text { Sementes }\end{array}$ & Número & 1050 & IPA \\
\hline
\end{tabular}

Fonte: Dados da pesquisa (2016).

\section{RESULTADO E DISCUSSÃO}

Esse tópico trata da discussão dos resultados obtidos sobre o desenvolvimento sustentável no meio rural do município de Triunfo (PE) em suas três dimensões.

\subsection{DIMENSÃO SOCIAL}

VS1 - Associações de comunidades rurais, membros participantes e funcionamento.

Os indicadores de estudo dessa dimensão possibilitaram delimitar um quadro acerca da organização e articulação das comunidades rurais, através da participação dos agricultores em nível da organização social, para resolver problemas e demandas, incluindo-se aqui os mais diversos tipos de associações comunitárias.

Segundo dados do COMDESTRI e do STR, o município possui 36 comunidades rurais, dentre as quais 33 estão organizadas de forma direta através de Associações Comunitárias e funcionam organizadas em seis Polos (Brejinho, Canaã, Central, Espírito Santo, Jericó e Micro-Ondas) criados pelo COMDESTRI. As demais que não 
possuem associações estão vinculadas à associação mais próxima da sua localidade, através da qual seus agricultores(as) também se fazem representar.

Aplicando o indicador quantitativo, que buscou medir o nível de organização social das comunidades rurais ( $\mathrm{IS}_{1}=33 / 36=0,92$ ou 92\%), pôde-se concluir que há uma significativa articulação das comunidades, na forma de associação rural.

No município, as associações representativas e organizadas de trabalhadores rurais agregam um total de 1.405 agricultores(as) que se articulam para tratar os principais temas de produção e do bem comum em busca de melhorar as condições de vida de suas comunidades rurais. Essa questão é apresentada por Falcão e Oliveira (2003), os quais destacam a importância da junção das associações como relevante e fundamental na luta por interesses coletivos e garantia do desenvolvimento e melhoria da qualidade de vida no campo.

No que se refere ao universo de pessoas associadas, quando se considera segundo o IBGE (2010) a população rural de 7.062 pessoas ou de famílias rurais em um total de 1.844 , com 3,8 pessoas por família, pode-se afirmar que o município é atendido nessa instância de empoderamento no meio rural, com uma representatividade bastante significativa, levando-se em conta que o número de associados chega aos 1.405 e que cada um deles potencialmente representa uma família rural, chega-se a 5.339 pessoas vinculadas direta e indiretamente às associações.

Portanto, é possível afirmar que o universo de pessoas atendidas por este tipo de organização abrange boa parte da totalidade dos moradores rurais do município ( $\mathrm{IS}_{2}=5339 / 7062=0,76$ ou 76\%), fator que ganha relevância por esta população encontrar-se inserida em um cenário relativamente bem estruturado quanto à organização e articulação em busca da solução para os seus problemas locais. Embora haja casos em que a associação tenha um número de associados que chegue a 100, mas a maioria das associações rurais ainda possuem uma quantidade pequena de associados; mesmo sendo esses associados chefes de família. A média de membros por associação é ainda baixa $\left(\mathrm{IS}_{3}=1405 / 33=42\right)$, conforme mostra o indicador.

As ações sociais são imprescindíveis para que o desenvolvimento sustentável se estabeleça, pois asseguram a continuidade da melhoria da qualidade de vida dos(as) agricultores(as) independente do programa ou projeto que esteja sendo implantado (FALCÃO; OLIVEIRA, 2003). 


\section{VS2 - Participação das associações rurais em ações sociais e nos Projetos de Programas Sociais do município.}

Acerca das ações sociais do Governo, no tocante à geração de renda no meio rural, a Aposentadoria Rural destaca-se como a mais importante para a população do campo por ser uma renda regular e estável, o que garante a melhoria na qualidade de vida e assegura o acesso aos bens e serviços básicos, e também por ampliar significativamente essa renda de famílias que vivem somente da agricultura (SAMPAIO; SABBAG; VITAL; SAMPAIO, 2008) e mantê-las no campo, principalmente em períodos de seca prolongada. Também se evidencia o recurso financeiro que chega ao município para a Aposentadoria Rural e que é um grande responsável por movimentar a economia local, juntamente com a produção agropecuária.

De acordo com a presidência do Sindicato dos Trabalhadores Rurais de Triunfo (PE), no que diz respeito à Pensão Rural, cerca de 500 pensionistas rurais recebem esse benefício previdenciário, chegando mensalmente a um valor de $\mathrm{R} \$$ $468.500,00$ que circula no município. E 41\% dos(as) agricultores(as) possuem Aposentadoria Rural, através da qual o município recebe mensalmente recurso financeiro da ordem de $\mathrm{R} \$ 2.720 .111,00$. Por ano, o município recebe de Aposentadoria Rural o valor de $\mathrm{R} \$ 32.641 .332,00$ que chega a ser bem maior que o Fundo de Participação do Município - FPM, cujo valor no ano de 2016 foi de $\$$ \$ 12.099.495,28.

Por outro lado, existem as tecnologias sociais de convivência com o semiárido, implantadas através das ONGs. O indicador quantitativo procurou identificar o nível de ações sociais do governo em programas e projetos de tecnologias sociais para o meio rural que atingem as associações rurais e concluiu que, apesar de serem fundamentais para o desenvolvimento, ainda é muito restrito o alcance desses projetos conforme mostra o valor registrado ( $\mathrm{IS}_{4}=10 / 33=0,30$ ou $30 \%$ ). 


\subsection{DIMENSÃO ECOLÓGICA}

\section{VE1 - Principais problemáticas ambientais existentes}

De acordo com a Associação de Desenvolvimento Rural Sustentável - ADES$\mathrm{SU}$, os problemas ambientais mais graves constatados no município consistem na prática das queimadas e em desmatamentos e são disseminadas em todas as comunidades rurais. $\mathrm{O}$ assoreamento de mananciais, a degradação dos solos agricultáveis da fauna e da flora vêm em consequência dessas práticas.

\section{VE2 - Projetos de proteção ambiental e de agricultura sustentável existentes}

Devido a essa degradação de recursos naturais, a ADESSU Baixa Verde e o Centro SABIÁ atuam em comunidades rurais com projetos de proteção ambiental como a implantação de sistemas agroflorestais, principalmente em áreas de nascentes dos riachos e rios por se tratarem de Áreas de Preservação Permanente.

Na perspectiva de recuperar os recursos naturais, a ADESSU, em parceria com a Agência Pernambucana de Águas e Clima - APAC, atua com um projeto de revitalização de nascentes degradadas em dois riachos do município abrangendo diretamente as comunidades do sítio Brejinho dos Soares, sítio Coroas e Sítio Icó e constituem um total de 123 famílias e 446 pessoas residentes nessas comunidades.

A destruição das nascentes e demais fontes de água refletem em questões econômicas das famílias agricultoras, gerando uma queda na produção devido à falta de água para o cultivo de alimentos para o consumo humano e dos animais.

Mas, apesar de sua importância estratégica para recuperação de áreas degradadas, dada a magnitude do município em número de comunidades rurais, ainda é pequeno o número de projetos de sustentabilidade realizados na esfera ecológica. Os projetos de proteção ambiental são encontrados em apenas poucas associações $\left(\mathrm{IE}_{1}=5 / 33=0,15\right.$ ou $\left.15 \%\right)$ e os projetos de agricultura sustentável também $\left(\mathrm{IE}_{1}=\right.$ $4 / 33=0,12$ ou $12 \%)$. 
VE3 - Associações que atuam com ações e projetos ambientais e de agricultura sustentável

Embora ainda seja pequeno o número de ações, de projetos ambientais e de agricultura sustentável, diante da necessidade da área rural no município, este tipo de intervenção já está sendo adotada pela maioria das associações rurais, conforme mostra o indicador $\left(\mathrm{IE}_{3}=5+4+11 / 33=20 / 33=0,60\right.$ ou $60 \%$ ). Uma das ações mais significativas, diz respeito à educação ambiental amplamente difundida pela rede escolar e pelas associações.

\subsection{DIMENSÃO ECONÔMICA}

VEc1 - Evolução do produto interno bruto do setor agropecuário no município

A linha de evolução do PIB Agropecuário de Triunfo (PE) mostra-se crescente, sai em 1999 de $\mathrm{R} \$ 907.000,00$ para $\mathrm{R} \$$ 5.329.000,00 em 2011 (IBGE, 2016). O PIB per capita no meio rural também, sai em 2000 de $\mathrm{R} \$ 169,31$ para $\mathrm{R} \$ 817,19$ em 2010 (IBGE 2000; 2010; 2016), devido principalmente ao fator econômico fortalecido decorrente dos programas de apoio à agricultura familiar no município, entre os quais se destacam o Programa de Aquisição de Alimentos (PAA), o Programa de Fortalecimento da Agricultura Familiar (PRONAF) e o Programa Nacional de Aquisição de Alimentos (PNAE). No entanto, após o ano 2011, apresentou uma significativa queda e essa queda agravou-se ainda mais nos últimos anos pelo expressivo quadro de escassez hídrica (Tabela 1), considerado o pior dos últimos 60 anos. É importante notar que as medidas pluviométricas para o município nos últimos cinco anos, em apenas 2014 alcança a média histórica de 1.200 milímetros. 
Tabela 1. Quantitativo de chuvas em Triunfo (PE)

\begin{tabular}{lc}
\hline ANO & MILÍMETROS \\
\hline 2012 & 300 \\
2013 & 720 \\
2014 & 1232 \\
2015 & 382 \\
2016 & 644 \\
\hline
\end{tabular}

Fonte: APAC - Posto Pluviométrico no 128 de Triunfo (PE), jan. 2017.

A falta de água trouxe consequências que impactaram negativamente na renda das famílias agricultoras, o que tirou de circulação um grande quantitativo de recursos financeiros que comumente girava em todo o comércio da região, oriundo da comercialização dos produtos agropecuários advindos do campo.

Diante disso, é enfatizado que antes da grande seca iniciada em 2012, particularmente no período de 2000 a 2010, a produtividade no campo aumentou, de modo que, mesmo com a queda da população rural (IBGE, 2010), as atividades produtivas mantiveram-se e foram suficientes para o crescimento do PIB per capita da população rural do município.

Este fator pode ser atribuído à importante política pública direcionada à agricultura familiar pelo Governo Federal, que empreendeu esforços e recursos em áreas básicas como o financiamento da produção de pequenos produtores a partir do PRONAF, política amparada pelos bancos oficiais, como também pelas políticas que estimularam a produção e absorveram em quantidade expressiva os produtos oriundos deste segmento agropecuário (Terra Pronta e Distribuição de Sementes, PAA e PNAE).

\section{VEc2 - Evolução das atividades da agropecuária no município}

Entre as principais atividades da agropecuária no município estão o café, a banana, o milho, o feijão e a cana-de-açúcar. Nos últimos 12 anos essas culturas apresentaram elevação dos índices de produtividade, mas nos últimos anos, devido ao ciclo da seca que iniciou em 2012, esses índices de produtividade agrícola decli- 
naram devido ao longo período de estiagem registrada na região do Semiárido. A cana-de-açúcar foi a cultura mais impactada por necessitar de grande quantidade de água que não teve disponível.

Já na atividade pecuária, o rebanho caprino ganhou ainda mais importância nesse período de grande seca, como vem sendo nos últimos cinco anos, em consequência do esvaziamento de muitas fontes de água que limitou as condições para criação de animais de maior porte. Assim, dada a sua robustez e resistência ao clima seco, o rebanho caprino se tornou uma alternativa econômica viável para os agricultores que passaram a ampliar seus plantéis.

\section{VEc3 - Programas e projetos de apoio à atividade agropecuária sustentável}

Estabelece-se aqui uma importante relação entre a agricultura familiar do município e os Programas do Governo Federal como o PRONAF, o PAA e o PNAE, e os Programas Terra Pronta e de Distribuição de Sementes; pois é através desses programas que os produtores rurais produzem e comercializam produtos de forma sustentável e asseguram a renda gerada pela atividade agropecuária.

Conforme Nunes (2007), o PRONAF se constitui em mais um importante mecanismo da política agrícola para a agricultura familiar, cujo objetivo é apoiar financeiramente as atividades do campo realizadas através da força de trabalho do agricultor e de sua família. Em Triunfo, o órgão responsável pelo Programa é a Secretaria Municipal de Agricultura e o IPA.

Segundo o IPA, em Triunfo as famílias agricultoras aplicam esse recurso principalmente em financiamento para custeio e investimento de atividades agrícolas, entre os quais a compra de insumos e materiais necessários à produção agrícola e a compra de equipamentos e maquinários utilizados no campo.

Em 2016 tinham acesso a esse crédito rural apenas 1.900 produtores nas modalidades Pronaf B e Pronaf Semiárido, cobrindo aproximadamente 1/4 dos agricultores de estabelecimentos da agricultura familiar $\left(\mathrm{IEc}_{1}=1900 / 7364=0,26 \mathrm{ou}\right.$ 26\%). Isso devido ao fenômeno da seca que limitou a produção agropecuária e, por conseguinte, ocasionou a diminuição e, até mesmo, perda de produção e redução de produtividade no setor. 
Por outro lado, segundo o Sindicato dos Trabalhadores Rurais de Triunfo, o PAA tem uma importante influência econômica em dois aspectos: o primeiro está relacionado ao perfil dos produtos agrícolas do município, oriundos da agricultura familiar de base orgânica e agroecológica; o segundo diz respeito à comercialização desses produtos que gera novas oportunidades de renda na base agrícola familiar.

Nessa mesma direção, os autores Lima, Evangelista e Gamarra-Rojas (2006) citam esses benefícios para os produtores rurais. Contudo, pôde-se identificar que ainda é baixa a participação de agricultores familiares nos benefícios do PAA, conforme mostra o indicador encontrado ( $\mathrm{IEc}_{2}=2035 / 7364=0,28$ ou $28 \%$ ).

Já o PNAE, considerando a realidade de Triunfo (PE), deu ênfase ao objetivo de garantir a alimentação dos alunos matriculados na educação infantil e no ensino fundamental ligados à rede municipal de educação e a uma instituição filantrópica da cidade, bem como a pessoas em situação de insegurança alimentar e nutricional, atendidas por programas sociais locais.

Assim, e de acordo com o STR no município, evidencia-se a importância do PNAE para os agricultores familiares. A Cooperativa de Produção e Comercialização da Agricultura Familiar Agroecológica - COOPCAFA é quem fornece ao governo municipal produtos orgânicos e agroecológicos diversificados e de qualidade.

Além disso, o recurso financeiro mensal que chega através do PNAE para o município é de $\mathrm{R} \$ 240.020,00$, dos quais 30\%, ou seja, $\mathrm{R} \$ \mathbf{7 2 . 0 0 6 , 2 4}$ são destinados à Agricultura Familiar que, em termos de beneficiários diretos, atinge cerca de 1.873 agricultores.

$\mathrm{O}$ indicador quantitativo buscou avaliar o alcance desse programa em termos da população das comunidades rurais e permitiu concluir que ainda atinge um número pequeno de agricultores familiares, conforme é mostrado pelo indicador dessa participação $\left(\mathrm{IEc}_{3}=1873 / 7364=0,25\right.$ ou 25\%).

Os Programas Terra Pronta e Distribuição de Sementes foram implantados em Triunfo pelo Estado e a municipalidade desde 2007. São muito importantes para a economia agrícola do município, considerando que é através deles que produtores rurais asseguram as condições de plantio, através do preparo do solo, aração da terra, e plantio mediante o recebimento das sementes; condições essenciais à produção como reportam Santos et al. (2012). 
Os técnicos do IPA orientam os agricultores sobre o tempo oportuno para preparar o solo. Nos últimos cinco anos, em que o fenômeno da seca se alastrou, os agricultores mantêm-se informados sobre as precipitações para tirarem o melhor proveito nessa situação adversa. As principais sementes distribuídas aos agricultores do município são das tradicionais culturas de subsistência milho e feijão, cujo cultivo depende exclusivamente das chuvas.

Para uma melhor análise, os indicadores quantitativos $\left(\mathrm{IEc}_{4}=1050 / 1405\right.$ $=0,75 \mathrm{ou} 75 \% \mathrm{e} \mathrm{IEc}_{5}=1050 / 1405=0,75 \mathrm{ou} 75 \%$ ) mostram que a grande maioria dos agricultores das associações rurais participa dos programas Terra Pronta e Distribuição de Sementes.

É fundamental enfatizar a importância que esses programas têm para a agricultura familiar. No ano de 2014 foram atendidos em torno de 500 agricultores e em 2015 a distribuição dobrou, quando 1030 agricultores residentes nas comunidades rurais receberam sementes. Esse aumento tem sua razão, a esperança dos agricultores em obterem bons resultados, após terem passado por 2014, ano favorável, quando se registrou a maior média histórica de chuvas que caíram na localidade nos últimos cinco anos.

\section{CONSIDERAÇÕES FINAIS}

Analisando a sustentabilidade do meio rural de Triunfo (PE) pode-se afirmar que em relação à dimensão social, o nível de empoderamento no campo é bastante expressivo pela via das associações comunitárias, onde as ordens religiosas tiveram um papel importante nesse processo de organização. Na dimensão ecológica, os problemas são conhecidos e recorrentes, ou seja, queimadas, desmatamentos, assoreamento de mananciais e degradação de solos agricultáveis devido à erosão. Ações de revitalização de mananciais, embora tímidas, têm sido adotadas, o mesmo ocorre em relação à execução de projetos de agroecologia e de agricultura sustentável. Nesse campo tem sido forte a educação ambiental através das associações de agricultores e a rede escolar. Na dimensão econômica, a coordenação de esforços do setor público e de organizações não-governamentais em prol da agricultura familiar 
tem se dado através de diversos programas e projetos importantes, compreendendo assistência técnica, crédito rural, apoio no plantio e na comercialização da produção. Nesse período de seca prolongada no município houve retração da atividade agrícola e expansão da atividade pecuária caprina que se adapta melhor às restrições hídricas reduzindo os riscos de perda dos agricultores. Em termos da análise conjunta das três dimensões do desenvolvimento sustentável, na social destaca-se a nucleação das comunidades em associações, dado a elas grande capacidade de organização e mobilização para defesa de seus interesses, nas mais diversas instâncias. Na econômica o destaque tem sido à adaptação produtiva e o apoio pelas agências oficiais e de organizações cooperativas à produção e à comercialização da agricultura familiar. Na ecológica, apesar do destaque à educação ambiental, as outras ações têm sido limitadas, situação que deve melhorar com o cadastro ambiental dos estabelecimentos que está sendo realizado. Daí a ocorrência de assimetrias entre essas três dimensões do desenvolvimento sustentável no meio rural dessa municipalidade.

\section{REFERÊNCIAS}

APAC - Agência Pernambucana de Águas e Clima. Posto Pluviométrico no 128 de Triunfo (PE). Disponível em: < http://www.apac.pe.gov.br>. Acesso em: 03 jan. 2017.

BARROS JUNIOR, G.; SANTOS, J. A.; FERNANDES, A. C.; BISOL, D. E. A Caatinga Guardiã da Água. Afogados da Ingazeira, PE: Asa Branca, 2015. 40 p. Disponível em: <www.radiopajeu.com.br>. Acesso em: 13 fev. 2016.

BORN, R. H. Agenda 21: legado da Rio 92 e instrumento para transformação social. In: BORN, R. H. Diálogos entre as esferas global e local: contribuições de organizações não-governamentais e movimentos sociais brasileiros para sustentabilidade, equidade e democracia planetária. São Paulo: Peirópolis, 2002. p. 7-18.

BRASIL. Decreto n $^{\circ} \mathbf{7 4 . 7 9 4}$, de 30 de outubro de 1974 (Dispõe sobre a criação do 
Programa de Desenvolvimento de Áreas Integradas do Nordeste-POLONORDESTE) Diário Oficial (da) República Federativa do Brasil. Brasília, 31 de outubro de 1974. Disponível em: < http://www.planalto.gov.br>. Acesso em: 02 ago. 2016.

BURSZTYN, M. A. A.; BURSZTYN, M. Desenvolvimento sustentável: biografia de um conceito. In: NASCIMENTO, E. P.; VIANNA, J. N. S. (Org.). Economia, meio ambiente e comunicação. Rio de Janeiro: Garamond, 2006. 184 p.

CONDRAF. Síntese da Política de Desenvolvimento do Brasil Rural (Proposta aprovada no dia 24 de fevereiro de 2010). Brasília: MDA, 2010a. Disponível em: $<$ http://www.mda.gov.br >. Acesso em: 10 fev. 2016.

\section{CONDRAF. Projeto de Lei da Política de Desenvolvimento do Brasil Rural} (Proposta aprovada no dia 08 de dezembro de 2010). Brasília: MDA, 2010b. Disponível em: < http://www.mda.gov.br>. Acesso em: 12 fev. 2016.

FALCÃO, R. B. de M.; OLIVEIRA, A. P. da S. Desenvolvimento Rural Sustentável: um guia prático para as comunidades do Semiárido Nordestino. Natal: Ed. Independente, 2003. 106 p.

FERREIRA, L. C. (Org.) A questão ambiental na América latina: teoria social e interdisciplinaridade. Campinas: Ed. da Unicamp, 2011. 97 p.

GOMES, J. M. Uma retrospectiva dos programas de desenvolvimento regional integrados - PDRI'S. Revista de Políticas Públicas, São Luís,.v. 2, n. 1, p. 45-78. jan./jul. 1996.

GOVERNO DO BRASIL. Meio Ambiente: Acordos Globais. Publicado em 28 jan. 2012. Disponível em: < http://www.brasil.gov.br > Acesso em: 04 ago. 2016.

IBGE - Instituto Brasileiro de Geografia e Estatística. Indicadores de Desenvolvimento Sustentável: Brasil 2002. Rio de Janeiro: IBGE, 2002. 195 p. Disponível em: < https://biblioteca.ibge.gov.br>. Acesso em: 12 jun. 2016.

IBGE - Instituto Brasileiro de Geografia e Estatística. Censo Demográfico 2000. Disponível em: < https://ww2.ibge.gov.br> Acesso em: 08 mar. 2016. IBGE - Instituto Brasileiro de Geografia e Estatística. Censo Agropecuário 2006. 
Disponível em: < http://cidades.ibge.gov> Acesso em: 14 fev. 2016.

IBGE - Instituto Brasileiro de Geografia e Estatística. Censo Demográfico 2010. Disponível em: < https://ww2.ibge.gov.br > Acesso em: 08 mar. 2016.

IBGE - Instituto Brasileiro de Geografia e Estatística. Cidades. Disponível em: $<$ https://cidades.ibge.gov.br> . Acesso em: 10 mar. 2016.

LAYRARGUES, P. P. Do ecodesenvolvimento ao desenvolvimento sustentável: a evolução de um conceito? Proposta, Rio de Janeiro, v. 24, n. 71, p. 1-5, 1997.

LIMA, M.; EVANGELISTA, J.; GAMARRA-ROJAS, C. Produção agroecológica e acesso a mercados locais. Recife: Diaconia, 2006. 56 p.

MALHEIROS, T. F.; PHLIPPI JÚNIOR, A.; COUTINHO, S. M. V. Agenda 21 Nacional e Indicadores de Desenvolvimento Sustentável: contexto brasileiro. Revista Saúde e Sociedade, São Paulo, v. 17, n. 1, p. 7-20, jan./mar. 2008.

MMA - Ministério do Meio Ambiente. Agenda 21 Brasileira: avaliação e resultados. Brasília, 2012. 86 p. Disponível em: < http://ivroaberto.ibict.br>. Acesso em: 07 ago. 2016.

NABUCO, M. R. A (des)institucionalizacão das políticas regionais no Brasil. Revista Eletrônica de Ciências Humanas e Sociais, v. 1, n. 2, p. 65-88. 2007. Disponível em: <http://www.uff.br>. Acesso em: 12 mar. 2017.

NUNES, S. P. O crédito rural do Pronaf e os recentes instrumentos de política agrícola para a agricultura familiar. Boletim Eletrônico - Conjuntura Agrícola, Curitiba, $n$. 156, 2007.

SACHS, I. Pensando sobre o desenvolvimento na era do meio ambiente. In: STROH, P. Y. (Org.). Caminhos para o desenvolvimento sustentável. 2. ed. Rio de Janeiro: Garamond, 2002. p. 47-64.

SAMPAIO, Y. de S. B.; VITAL, T. W. Desenvolvimento sócio-econômico-ambiental: conceito e problemas para mensuração. Reflexões Econômicas. v. 1, n. 1, p. 249274. Recife, abr./set. 2015. 
SAMPAIO, Y.; SABBAG, W. J.; VITAL, T.; SAMPAIO, G. R. Perfil de Entrada do Projeto Dom Hélder Câmara: Território do Sertão Sergipano. Sergipe: ADUFERPE, 2008. $261 \mathrm{p}$.

SANTOS, A. de S. dos; CURADO, F. F.; SILVA, E. D. da.; PETERSEN, P. F.; LONDRES, F. Pesquisa e Política de Sementes no Semiárido Paraibano: Relatório. Aracaju: Embrapa Tabuleiros Costeiros, 2012. 60 p.

SILVA, R. M. A. da. Entre o combate à seca e a convivência com o Semiárido: transições paradigmáticas e sustentabilidade do desenvolvimento. Fortaleza: Banco do Nordeste do Brasil, 2008. n. 12, 274p.

SILVA, C. L. d.; SOUZA-LIMA, J. E. de. (Org.). Políticas públicas e indicadores para o desenvolvimento sustentável. Saraiva. São Paulo, 2010. 338p.

SIMÃO, A. G.; SILVA, C. L.; SILVA, H. P. E.; CASTANHEIRA, M. A. V.; JUREC, P. S. S.; WIENS, S. Indicadores, políticas públicas e a sustentabilidade. In: SILVA, C. L.; SOUZA-LIMA, J. E. (Org.). Políticas Públicas e Indicadores para o Desenvolvimento Sustentável. Saraiva. São Paulo, 2010. v. 1, p. 83-125.

VARELLI, L.; ROMANO, J. O.; ANTUNES, M.; NABUCO, R. Mapeamento de experiências de monitoramento de políticas públicas pela sociedade civil no Brasil. 2009. In: ROMANO, J. O.; HERINGER, R. (Org.). A Política vivida: olhar crítico sobre monitoramento de políticas públicas. Rio de Janeiro: Actionaid - Ford Foundation, 2011. $432 \mathrm{p}$.

Recebido em: 18/07/2017 Aceito em: 24/05/2018 